\title{
Ecology and status of lesser cats and other small carnivores in India
}

\author{
Samujjal Saharia \& Prasanta Kumar Saikia* \\ Department of Zoology Gauhati University, Guwahati, Assam 781014, India \\ *Corresponding author, e-mail: saikiapk@rediffmail.com
}

\begin{abstract}
Small carnivores play a significant role in regulating the ecosystem as they are crucial predators, prey, and seed dispersers. South-east Asia, including India, has a rich assemblage of several species of these carnivores. India is home to a rich variety of small carnivores belonging to the Families Felidae, Mustelidae, Viverridae, and Procyonidae. Habitat use by these carnivores is primarily influenced by food availability and interaction with other species. Often, they are threatened by illegal hunting, human encroachment, increasing urbanization, and industrialization. However, very little research has focussed on their conservation and management. Therefore, in the present review, an attempt has been made to evaluate the distribution, ecology, habitat use, and activity patterns of small carnivores in India concerning Southeast Asia. Scats, footprints, and camera traps are primarily used for their detection in a given area. Small carnivores show varying habitat and food preferences. They are mostly nocturnal and elusive in behavior tmaking their detection difficult in a particular site. No significant differences were observed in their activity patterns during dry and wet seasons. Some of the carnivores are arboreal, which poses another limitation to study them through camera-traps set at or little above the ground level. Though several studies have been conducted on their ecology, still, there are gaps in our knowledge that require a better understanding of their habitat use and activity patterns using advanced methods. This study provides an overview of the habitat ecology and activity patterns of some small carnivores, along with the limitations and future research prospects.
\end{abstract}

KEY WORDS

Activity pattern; camera-trap; elusive; Felidae; habitat use; Mustelidae; Procyonidae; small carnivore; Viverridae.

Received 15.06.2021; accepted 05.11.2021; published online 16.12.2021

\section{INTRODUCTION}

Tropical small carnivores play a significant role in regulating the ecosystem as they are crucial predators, prey, and seed dispersers (Mudappa et al., 2007). However, only a handful of research has focused on their ecological roles and activity patterns (González-Maya et al., 2009). For effective management and conservation, a better understanding of functional activities of these carnivore communities is of utmost importance (Chen et al., 2009). Ecosystem dynamics are directly im- pacted by changes such as population growth and decline in small carnivore communities (González-Maya et al., 2009). Differences in body size, morphology, and habitat specialization contribute to the species richness of small carnivores compared to the larger ones (Kalle et al., 2014).

Several factors such as availability of food and interaction with other species greatly influences the habitat of animals. Foraging is essential while keeping themselves safe from potential predators (Chutipong et al., 2017). The decline of large, medium and small carnivores is a global concern. 
Most tropical countries are rich in the number of carnivore species. Despite the fast depletion of wildlife during the present century, India still has a remarkable variety of large and small mammals (Corbet \& Hill, 1992). However, very little is known about the biology of medium and small-sized carnivores such as jungle cats (Felis chaus), leopard cats, fishing cats, common leopard, etc., in India. Mammalian carnivore communities are adversely affected by urban development (Ordeñana et al., 2010). In the Indian subcontinent, small carnivores' species richness is centered in the Eastern Himalayas, the North-east Hills, and the Western Ghats (Sterndale, 1884; Datta et al., 2008). About 33 species of small carnivores are found in India (Corbet \& Hill, 1992), out of which more than $50 \%$ occur in northeast India (Mudappa, 2013). India is especially rich in species diversity mainly because of the convergence of three Bio-geographic realmsIndomalayan, Palearctic and Ethiopian (Mani, 1974).

Moreover, in sympatric carnivore communities, small carnivores live with large carnivores, making the small carnivores vulnerable to the larger ones, increasing interspecific competition. Thus, the habitat use of small carnivores is influenced by their predation by larger predators. For example, it is seen that large cats (Tiger and leopards) in Thailand feed on palm civets, Paradoxurus hermaphroditus (Pallas, 1777), small-Indian civets Viverricula indica Geoffroy Saint-Hilaire, 1803, and other such species (Chutipong et al., 2017).

Habitat loss, fragmentation, depletion in prey populations, poaching, and persecution are welldocumented threats for carnivore species (Inskipp \& Zimmerman, 2009). Habitat quality, prey availability, and prevailing disturbances have long been recognized as the primary influences in determining carnivore use and abundance in a given area, with habitat selection models the primary tool for identifying those relationships. Carnivores being placed at the top-level trophic position are considered potential indicators of the ecosystems' overall fate (Ordeñana et al., 2010; Crooks et al., 2010). Felids are widely distributed throughout the world. Most of these species face serious threats as they constitute a crucial component of biodiversity by playing a functional role at the food chain's top. The methods primarily used to detect felids' presence are the scats, footprints, and camera traps (Douglas de Carvalho et al., 2015). However, some carni- vores, such as viverrids and felids, are arboreal and are rarely detected by camera traps (Chutipong et al., 2014). Among medium and small carnivores, the jungle cat is the most common wild felid in India. It inhabits many habitats, and the common leopard is among those mammals known for its primarily adaptable habit.

Although our understanding of their distribution and ecology has increased, comprehensive information at a regional scale in most parts of the country is still lacking. The extreme difficulty in physically observing them and the inaccessibility of their habitat is one of the common issues in carnivore research due to their elusive behavior and rarity, making it most challenging to study in the wild. Effective conservation of these small carnivores requires detailed knowledge of their current distribution, population status, and ecological requirements. Therefore, it would be helpful to study carnivore species while attempting to measure the effect of rapid urbanization on ecosystem health. In the present review, we tried to overview the ecology, habitat use, and activity patterns of small carnivores in India concerning Southeast Asia.

\section{MATERIAL AND METHODS}

A thorough literature survey was done in the present study, including several open access research articles, book chapters, communications, and research papers published in some peer-reviewed journals. Research articles related to the small carnivores of India were mainly emphasized. Articles including very old to recent are considered in developing this article. Spellings of the small carnivore names and certain wordings mentioned in cited literature are kept the same in this article also.

\section{RESULTS}

\section{Ecology, activity patterns, and habitat use by small carnivores}

Species belonging to a small carnivore community often feed on various sources, including invertebrates, fruits, birds, and small mammals. Therefore, this small carnivore community serves as a good indicator of biodiversity at the ecosystem and species level. Also, they play a significant role in 
the habitat as major seed dispersers and predators. Therefore, there has been increasing interest in recent years to study these small carnivores' ecological role for their conservation and management (Mudappa et al., 2007). The most commonly used tool to study mammalian carnivores' ecology and activity patterns is camera traps, a noninvasive survey method (Carbone et al., 2001; Ordeñana et al., 2010) to document species richness and assess status (Datta et al., 2008). Carnivores have mostly secretive behavior, nocturnal activity, low densities, and humans' wariness (Datta et al., 2008). Southeast Asian forests harbor several civet species (Datta et al., 2008). To date, very little support has been provided for targeted studies to assess felid distribution of Southeast Asia (McCarthy et al., 2015).

The habitat use and activity patterns of a small carnivore community in Southern Taiwan were studied, including four species that showed that Viverricula indica, Pagumalarvata, and Melogalemoschata were nocturnal while Herpestes urva (Hodgson, 1836) is diurnal. Moreover, their habitat ranged from areas with high moisture, flatter slopes to areas with high canopy cover. Furthermore, no significant differences were observed in the activity patterns between the dry and wet seasons (Chen et al., 2009). For the development of management strategies of Sumatran Wildlife, an assessment on the six small felids species-the leopard cat, Prionailurus bengalensis (Kerr, 1792), the Sunda clouded leopard cat, Neofelis diardi (G. Cuvier, 1823), the marbled cat, Pardofelis marmorata (Martin, 1836), the Asiatic golden cat, Pardofelis temminckii (Vigors $\&$ Horsfield, 1827), the flat-headed cat, Prionailurus planiceps (Vigors \& Horsfield, 1827), and the Sumatran tiger, Panthera tigris sumatrae Pocock, 1929, was conducted that revealed information about their habitat use and distribution. Temporal resource partitioning was showed among the sympatric species.

The clouded leopard and the leopard cat were mostly nocturnal, showing very little activity during the day. This nocturnal nature may be a mechanism to avoid human activity, while the marbled cat mostly exhibited a diurnal activity pattern. Often, the leopard cats experience a higher likelihood of habitat disturbance as they mostly utilize the edge of the forest areas that increase the risk of conflict with humans. Also, the study implies distributional overlap among the species (McCarthy et al., 2015). In Southeast Asia, the Jungle cat is a rare wild cat whose known distribution ranges from Vietnam, Thailand, China, Nepal, and India to the Eastern Mediterranean Region of Egypt. The Jungle cats mostly prefer thick vegetation close to water bodies (Baker et al., 2003).

Chen et al. (2009) provided information on habitat use and activity pattern of four small carnivore species, including small Indian civet Viverricula indica, masked palm civet Paguma larvata (Smith, 1827), crab-eating mongoose Herpestes urva (Hodgson, 1836), and ferret badger Melogale moschata (Gray, 1831) of Southern Taiwan, which revealed that sympatric carnivore species have varying diet, habitat use patterns and activity patterns thus influencing their coexistence. In India, the Western Ghats harbor a high plant and animal taxa diversity, including small carnivores.

Six small carnivores are encountered in the Western Ghats' rainforests, namely Martes gwatkinsi (Horsfield, 1851), Paradoxurus jerdoni Blanford, 1885, Herpestes vitticollis (Bennett, 1835), Herpestes fuscus Waterhouse, 1838, Viverricula indica, and Prionailurus bengalensis (Mudappa et al., 2007). Wide ranges of habitats for the small carnivores are offered by the Nilgiri Biosphere Reserve in Southern India. Furthermore, Mudumalai Tiger Reserve holds ten species of small carnivores such as Felis chaus Schreber, 1777, Prionailurus bengalensis, Prionailurus rubiginosus (Geoffroy Saint-Hilaire, 1834), Viverricula indica, Herpestes vitticollis, Herpestes smithii (Gray, 1837), Paradoxurus hermaphroditus, Paradoxurus jerdoni, Lutrogale perspicillata (Geoffroy Saint Hilaire, 1826), Herpestes fuscus.

The Mudumalai Tiger reserve wildlife is threatened by cattle grazing, human settlements, fishing, illegal hunting, and forest fires (Katte et al., 2014). There are three tropical carnivores, Masked palm civet Paguma larvata, Common palm civet Paradoxurus hermaphroditus, and yellow-throated marten Martes flavigula, negatively affected by the presence of leopards and other medium-sized carnivores. Also, the small and large predators were shown to have overlapping temporal activity, while food resources have little effect on these carnivores due to resource availability (Chutipong et al., 2017).

Furthermore, the Western Ghats is considered a World Heritage Site by the United Nations Educational, Scientific and Cultural Organisation (UNESCO). Small carnivore species, including small felids, herpestids, viverrids, and mustelids, 
are present there. Felis chaus was found to prefer low canopy cover, less precipitation, and live alongside human habitations. At the same time, the habitat preference of Viverricula indica ranged from scrubby jungles, grasslands, riverine areas to rainforests. They were also shown to have an affinity towards dense canopy cover. Herpestes smithii and Prionailurus hermaphrodites prefer dry forests, while Herpestes vitticollis have an affinity towards dense canopy cover (Kalle et al., 2013). Mustelids, Viverrids, and herpestids are mostly found in northeast India's rainforests, among which viverrids are the most species-rich (Datta et al., 2008).

Datta et al. (2008) recorded six species of small carnivores-Yellow-throated Marten, Ferret badger, Large Indian Civet, Common Palm Civet, MaskedPalm Civet, and Crab-easting Mongoose in Namdapha National Park, out of which the occurrence of Large Indian Civet was comparatively higher than the other species while only four species were captured in Pakke Wildlife Sanctuary, namely Large Indian Civet, Small Indian Civet, Common Palm Civet, and Crab-eating Mongoose. In Namdapha, these carnivores are also killed though not intentionally, but they fall into the other species' traps. There are very few records in the Indian sub-continent; however, Kakati \& Srikant (2014) reported the first camera-trap record of small-toothed palm civet Arctogalida trivirgata (Gray, 1832) from Meghalaya, India. Further, habitat of small carnivores is largely affected by habitat loss and fragmentation due to rapidly growing urbanization and industrialization. Species having specialized habitat requirements are negatively impacted by habitat fragmentation, while those having generalized requirements are positively affected (Mudappa et al., 2007).

\section{Study limitations}

Because the small carnivores are rarely sighted as they are primarily nocturnal, elusive, and secretive, very little information exists on their status, distribution, abundance, activity patterns, and ecology. Night walks along established trails to estimate encounter rates are time-consuming; however, camera-trapping is the most preferred method to observe these carnivores to document species richness and assess their status (Datta et al., 2008). But some small carnivores are also arboreal, which makes their detection difficult through camera traps set at the ground level (Chutipong et al., 2017). Very little support has been provided for targeted studies documenting felid distribution in Southeast Asia, ultimately making it difficult to execute large-scale and long-term tasks on these small cats (McCarthy et al., 2015).

\section{DISCUSSION AND CONCLUSIONS}

Current ecological knowledge reveals that small carnivores are necessary to maintain biodiversity and the ecosystem. They play a significant role in regulating the ecosystem as crucial predators, prey, and seed dispersers. Several factors such as availability of food and interaction with other species greatly influence animals' habitat. Habitat quality, prey availability, and prevailing disturbances have long been recognized as the primary influences in determining carnivore use and abundance in a given area. Sympatric carnivore species live together where the larger ones predate the smaller ones, thus increases interspecific competition. The presence of scats, footprints, and camera traps are the methods to detect the presence of these small carnivores; however, camera traps set at the ground level are not always effective as some carnivores are arboreal. Several studies conducted so far reveal that Southeast Asia has a rich assemblage of small carnivores. In India, species richness of small carnivores is centered in the Eastern Himalayas, the North-east Hills, and the Western Ghats. About 33 species of small carnivores are found in India, out of which more than $50 \%$ occur in northeast India. Numerous species of small carnivores are reported from different parts of Southeast Asia, including India. These carnivores are mostly nocturnal, elusive in behaviour, and are therefore rarely sighted. They have varying habitat preferences ranging from low canopy cover, less precipitation alongside human settlements, scrubby jungles, grasslands, riverine areas, and dry forests to dense canopy cover and rainforests. However, cattle grazing, human settlements, illegal hunting, and forest fires pose severe threats to the carnivores. No significant differences were observed in activity patterns during dry and wet seasons. Most of the carnivore species have overlapping temporal activity, thus reducing temporal avoidance.

Additionally, increasing human demands, rapid urbanization, and industrialization may affect biodiversity and ecosystem resiliency. Furthermore, 
very little conservation and research attention has been focused on the rich assemblage of small carnivores. For effective management and conservation, a better understanding of these carnivore communities' functional activities is of utmost importance using effective model surveys.

\section{REFERENCES}

Baker M.A., Nassar K., Rifai L., Qarqaz M., Al-Melhim W. \& Amr Z., 2003. On the current status and distribution of the Jungle Cat, Felis chaus, in Jordan (Mammalia: Carnivora). Zoology in the Middle East, 30: 5-10.

Carbone C., Christie S., Conforti K., Coulson T., Franklin N., Ginsberg J.R., Griffiths M., Holden J., Kawanishi K., Kinnaird M., Laidlaw R., Lynam A., Macdonald W., Martyr D., McDougal C., Nath L., O’Brien T., Seidensticker J., Smith D.J.L., Sunquist M., Tilson R. \& Wan Shahruddin W.N., 2001. The use of photographic rates to estimate densities of tigers and other cryptic mammals. Animal Conservation 4: 75-79. https://doi.org/10.1017/S1367943001001081

Chen M.-T., Tewes M.E., Pei K.J. \& Grassman L.I., 2009. Activity patterns and habitat use of Sympatric small carnivores in Southern Taiwan.Mammalia, 73: 20-26.

Chutipong W., Steinmetz R., Savini T. \& Gale G. A.,2017. Assessing resource and predator effects on habitat use of tropical small carnivores. Mammal research, 62: $21-36$

Crooks K.R., 2010. Community ecology of urban carnivores. Urban carnivores: Ecology, conflict, and conservation, pp. 185-196.

Datta A., Naniwadekar R. \& Anand M.O., 2008. Occurrence and conservation status of small carnivores in two protected areas in Arunachal Pradesh, north-east India. Small Carnivore Conservation, 39: 1-10.

Douglas de Carvalho W., Rosalino L.M., Dalponte J.C., Santos B., Adania C.H. \& Esbérard, C.E.L., 2015. Can footprints of small and medium sized felids be distinguished in the field? Evidences from Brazil's Atlantic Forest. Tropical Conservation Science, 8: 760-777.
González-Maya J.F., Schipper J. \& Benítez A., 2009. Activity patterns and community ecology of small carnivores in the Talamanca region, Costa Rica. Patrones de actividad y ecología de la comunidad de pequeñoscarnívoros de la región de Talamanca, Costa Rica. Small Carnivore Conservation, 41: 9-14.

Inskip C. \& Zimmermann A., 2009. Human-felid conflict: a review of patterns and priorities worldwide. Oryx, 43: 18-34.

Kakati K. \& Srikant S., 2014. First camera-trap record of smalltoothed palm civet Arctogalida trivirgata from India. Small Carnivore Conservation, 50: 5053.

Kalle R., Ramesh T., Qureshi Q. \& Sankar K., 2013. Predicting the distribution pattern of small carnivores in response to environmental factors in the Western Ghats. PLoS One, 8(11): e79295.

Kalle R., Ramesh T., Qureshi Q. \& Sankar K., 2014. Estimating seasonal abundance and habitat use of small carnivores in the Western Ghats using an occupancy approach. Journal of Tropical Ecology, 30: 469-480.

Mani M.S., 1974. Biogeographical evolution in India. In Ecology and biogeography in India . Springer, Dordrecht, pp. 698-724.

McCarthy J.L., Wibisono H.T., McCarthy K.P., Fuller T.K. \& Andayani N., 2015. Assessing the distribution and habitat use of four felid species in Bukit Barisan Selatan National Park, Sumatra, Indonesia. Global Ecology and Conservation, 3: 210-221.

Mudappa D., Noon B.R., Kumar A. \& Chellam R., 2007. Responses of small carnivores to rainforest fragmentation in the southern Western Ghats, India. Small Carnivore Conservation, 36: 18-26.

Mudappa D., 2013. Herpestids, viverrids and mustelids. Mammals of South Asia, 1: 471-498.

Ordeñana M.A., Crooks K.R., Boydston E.E., Fisher R.N., Lyren L.M., Siudyla S., Haas C.D., Harris S., Hathaway S.A., Turschak G.M., Miles K. \& Van Vuren, D.H., 2010. Effects of urbanization on carnivore species distribution and richness. Journal of Mammalogy, 91: 1322-1331.

Sterndale R.A., 1884. Natural history of the Mammalia of India and Ceylon. Thacker, Spink. 
